\title{
Using the Efficient Frontier to Obtain the Best Solution for the Storage Location Assignment Problem
}

\author{
Marcele Elisa Fontana and Cristiano Alexandre Virgínio Cavalcante \\ Departamento de Engenharia de Produção, Universidade Federal de Pernambuco (UFPE), Avenida Acadêmico Hélio Ramos, \\ s/n, Cidade Universitária, 50740-530 Recife, PE, Brazil
}

Correspondence should be addressed to Marcele Elisa Fontana; marcelelisa@gmail.com

Received 23 June 2014; Accepted 21 August 2014; Published 27 October 2014

Academic Editor: Pandian Vasant

Copyright ( 2014 M. E. Fontana and C. A. V. Cavalcante. This is an open access article distributed under the Creative Commons Attribution License, which permits unrestricted use, distribution, and reproduction in any medium, provided the original work is properly cited.

\begin{abstract}
The main variables that influence the efficiency of a warehouse are the use of space and the order picking distance. In the literature, there are proposals to add the costs with space and order picking in order to evaluate each alternative for storage location assignment. However, there were problems with the adoption of this methodology, including difficulties in determining the costs and tradeoffs between them. These difficulties can result in solutions that are suboptimal. Based on these facts, this paper proposes a class-based storage process and storage location assignment by a cube-per-order index (COI) that analyzes the space required and the total order picking distance by Pareto-optimal calculations. The efficient frontier possibilities allow the reduction of the set of alternatives, and the DM can analyze only the alternatives on efficient frontier.
\end{abstract}

\section{Introduction}

Warehouses are essential components of logistics and supply chains. The performance of warehouse operations significantly affects the efficiency of the whole chain to which it belongs [1]. Warehouse operations involve receiving, shipping, storing, and order picking, among other actions, and the coordinated optimization of all of these different operations is highly complex [2].

In its simplest form, an order arrives at the warehouse and an order picker is sent into the picking area with the customer's list to retrieve the requested items from storage [3]. One of the most important concerns of warehouse managers is finding the most cost efficient and time efficient way to pick orders placed by customers; this would allow the company to be known as a responsible company with satisfied customers [4]. The service level is composed of a variety of factors, including response time, order integrity, and accuracy. Thus, a crucial link between order picking and service level is that the faster an order can be retrieved, the sooner it is available for shipping to the customer. Minimizing the order retrieval time (i.e., picking time) is therefore a need for any order picking system [3].
Products typically arrive in large units, such as unit loads and standard or custom containers or pallets. However, customer order lists demand the transformation of these large arrival materials into small quantities and often for timely delivery $[5,6]$. Integrated information systems that allow retailers to order more frequently and in multiple items, usually smaller quantities, make this problem even more pronounced. This situation becomes more difficult in a disintermediation supply-demand system [7]. In this way, in global logistics systems, warehousing plays a critical role in ensuring high levels of customer service and overall supply chain performance [8].

However, most of the activities of material handling are repetitive and intensive hand labor is required to handle those small orders separately. Therefore, among operations costs in a warehouse, labor cost, principally the order picking cost, is significant $[6,8]$. Jane and Laih [9] defined order picking as "the process by which appropriate amounts of products are retrieved from specified storage locations to fulfill customer requests." In addition, according to Chen et al. [10] because these warehouse activities are common, even small improvements can achieve significant balances. 
Therefore, it is necessary to enhance the productivity and reduce the operational costs of the warehouse [1].

Warehouse managers can influence the responsiveness of their system through a number of controls, such as the capacity of the picking and sorting operations and the order picking policy used [11]. Therefore, the selection of an order picking method is a strategic decision because it has a wide impact on many other decisions in warehouse design and operation [12]. In this sense, four methods are usually used to reduce travel times or distances by means of more efficient control mechanisms in warehouses. They include (1) determining a good order of picking routes, (2) zoning the warehouse, (3) assigning orders to batches, and (4) assigning products to the correct storage locations [13].

Routing policies determine the route of a picker for a picking tour, which specifies the sequence in which SKUs are to be picked [14] which minimizes the travel distances by pickers. The average length of an order picking route can be calculated for two different routing policies, which are (1) distance traveled within the aisles and (2) distance traveled in the cross aisles [3].

Zoning means that a logical storage area (e.g., a pallet storage area, the entire warehouse, etc.) is split into multiple parts, each with a different order of pickers (i.e., an order picker picks only that part of an order that is in his/her assigned zone). Possible advantages of zoning include the fact that each order picker only needs to traverse a smaller area, reducing overall traffic congestion, and the possibility that order pickers become familiar with the item locations in their specific zone. The main disadvantage of zoning is that orders are split and must be consolidated again before shipment to the customer $[13,15]$.

Batch picking involves the assignment of a group of orders to a picker to be picked simultaneously in one trip [16]. With respect to order batching, two problem types can be distinguished: in offline (i.e., static) batching, all customer orders are known in advance; in online (i.e., dynamic) batching, customer orders become available dynamically over time [17]. So, the main decision involved in order batching problems is how a given set of customer orders should be combined such that the total length of all tours is minimized and determining which are necessary to collect all items [18]. However, when batching and/or zoning are applied, usually some additional effort is needed to split the batch and to consolidate the items per customer order or per destination to which the orders will be shipped. These processes are often called accumulation/sorting (A/S) [15].

Storage assignment is an important decision problem in warehouse operation management. It involves the placement of a set of items in a warehouse in such a way that some performance measure is optimal. The main purpose of using one storage location assignment system or combination of this is to establish the parameters for ease of identification and location of items in warehouse. Storage assignment methods typically make use of demand attribute information of order quantity, order frequency, and correlation between demands $[19,20]$.

Thus, the product location assignment in warehouses is a problem where the stock keeping units (SKUs) are assigned to storage positions in order to reduce the requirement for space and minimize the resulting picking effort when retrieving SKUs (i.e., minimize the total distance travelled or travel time throughout the warehousing process) [21, 22]. Furthermore, poor use of space has become common uneconomical behavior. Thus, one goal of warehouse management is to maximize the storage space available. Proper planning helps make moving and storage efficient and ultimately results in lower operating expenses [23].

Three storage location assignment policies were put forward by Muppani and Adil in 2008 [24], namely, dedicated or fixed storage, randomized or variable storage, and classbased storage (CBS). A dedicated storage policy prescribes a particular location for the storage of each product [25], such that no other item can be stored there, even if the space is empty. Systems with random storage are used because of the necessity of optimizing the storage area. The materials are placed in existing open spaces. Randomized and dedicated storage are extreme cases of class-based storage policy: randomized storage considers a single class and dedicated storage considers one class for each item $[26,27]$.

According to Fontana and Cavalcante [28], in dedicated storage, there is a rise in the cost of using space when such space is used poorly, while under random storage much effort is placed on the order picking system. Class-based storage combines features of the prior two systems and can be a good alternative for making a warehouse more efficient in terms of the space used and the order picking operation, as well as for minimizing warehouse costs.

Meghelli-Gaouar and Sari [29] proposed the class-based storage formation according to their request (i.e., total demand). They applied ABC analysis for this. However, before it, Hesket, in 1963, proposed the cube-per-order index (COI), which is expressed as the ratio of the storage space required (i.e., a cube) per SKU and the order frequency of the SKU [30]. According to Jane and Laih [9], the rule ranks the items in ascending order of the index and then assigns them in that order to the locations nearest to the input/output (I/O) point to reduce the cost of order picking. To Brynzér and Johansson [30], the storage location assignment by COI is justifiable because the components included in the same order have many different characteristics that could lead to components that are spread over a large geographical area.

However, determining the proper storage locations for potentially thousands of products is one major task that faces the warehouse manager during the design of a new warehouse or the refurbishment of an existing facility. There are many factors that affect storage assignment, including the order picking method, size and layout of the storage system, the material handling system, product characteristics, demand trends, turnover rates, and space requirements [26].

Many authors study the storage allocation problems to improve order picking performance (i.e., they aim to minimize the total order picking distance, time, or cost). Petersen and Aase [14] proposed the implementation of class-based storage. They concluded that the choice of how storage classes are assigned to storage locations has a major impact on the successful implementation of CBS. Daniels et al. [31] formulated a model that simultaneously determined 
the assignment of inventory and the associated sequence in which the selected locations are visited. Pan and $\mathrm{Wu}$ [32] proposed an algorithm to storage assignment into zones in a pick-and-pass warehousing system because of the growth of e-commerce. F. T. S. Chan and H. K. Chan [26] showed a study of a real case to improve the performance of picking by performing twenty-seven experiments on different combinations of storage assignment policies, routing policies, and pick densities. Chuang et al. [7] proposed the clustering-assignment problem model (CAPM) for item-associated cluster assignment. Ene and Öztürk [33] developed a mathematical model and stochastic evolutionary optimization approach to design a storage assignment and order picking system in the automotive industry. First, they solved the storage location assignment problem with a classbased storage policy with the aim of minimizing warehouse transmissions by using integer programming. Second, they considered the batching and routing problems together to minimize travel cost in warehouse operations. Xiao and Zheng [34] proposed a mathematical model to design a correlated storage assignment system by storing items with demand dependences together to minimize zone visits when picking materials/parts in a production line. The demand dependences can be obtained from the products' bill of materials (BOMs) and production rates. Boysen and Stephan [21] proposed a model to treat the deterministic product location problem (PLP) in different warehouse layouts. Kovács [20] proposed a system of mixed integer programming (MIP) for this problem in a warehouse characterized by multicommand picking and served by milk-run logistics where vehicles circulate according to a predefined schedule, often with multiple cycles (i.e., routes), serving different departments.

However, these authors did not consider reducing the total space required for storage. In this sense, Muppani and Adil $[24,27]$ proposed a simulated annealing approach and the Branch and Bound algorithm to solve the class formation and allocation problem of items in warehouses with the objective of minimizing the order picking distance of a single command (i.e., taking one product at a time) and of minimizing the total space required for storage. To evaluate these two criteria simultaneously, the authors proposed to analyze the total cost of order picking and space. Thus, the setup considered more efficient is that with the least cost. They compare their results with a dynamic programming algorithm by Van Den Berg [35]. Guerriero et al. [36] also considered the total cost in a multilayer warehouse with compatibility constraints among the classes.

Nevertheless, in some cases, there may be a tradeoff between space cost and order picking distance cost. In other words, the alternative chosen can be the best in a single criterion only (i.e., space or order picking) and will be poor in the other. This alternative does not meet the real needs of the warehouse. According to Chen et al. [37], a transformation of multiobjective functions into a single objective function cannot be the best choice for optimization. Moreover, in warehouses with high product turnover, a greater interest in smaller order picking distance than a greater economy in the space used is common. Thus, a cost analysis cannot be efficient for this case.
For these reasons, Fontana and Cavalcante [38] proposed the use of a multicriteria method called PROMETHEE. This method allows simultaneous evaluation of the different costs and assigns different weights to them in the final calculation. However, it is difficult for decision makers to compute the cost of storage particularly that cost related to the opportunity cost of wasted space. In addition, many decision makers have no knowledge of methods to support multicriteria decision. This fact implies a need of a facilitator to implement the method.

Therefore, based on these facts, this paper proposes a class-based storage formation and storage location assignment system using a cube-per-order index (COI) and analyzes the space required and total order picking distance using a Pareto-optimal curve. The Pareto-optimal curve gives the set of alternatives in a nondominated list. It assumes that the DM has more facilities to analyze the alternatives because the amount of alternatives will be smaller due the efficient frontier described by the Pareto-optimal curve.

The paper is organized as follows. In Section 2, the proposed methodology is described; Section 3 presents a description of the type of storage simulated; the results and analysis are given in Section 4; finally, concluding remarks are proposed.

\section{Proposed Methodology}

Here the proposed methodology will be presented. This proposal intends to describe a class-based storage system and storage location assignment by cube-per-order index (COI). With this system, it aims to minimize the space required and the total order picking distance. The analysis is made by Pareto-optimal curve. Figure 1 shows the steps of this proposal.

2.1. Preliminary Stage. In the first stage, the decision maker (DM) should obtain data about product characteristics, which include the type (i.e., how many different products there are), the products density and demand, and the space required for each product in the warehouse. Moreover, the warehouse characteristics are required, which include its dimensions (i.e., length and width), layout, picker capacity, and order picking policies (i.e., order picking in single command, in batching, per zone, per route, etc.).

2.2. Evaluation Stage. This stage generates a set of storage location assignment alternatives that may be viable. Based on the data from step 1 , the calculation of the COI is applied. This index is defined as the ratio between the spaces required for storing the item(s) (i.e., per unit of storage) and by popularity (i.e., demand/period), as follows:

$$
\mathrm{COI}_{c}=\frac{f_{d} *\left[\operatorname{Max} I_{p c}^{t}\right]}{D_{p c}},
$$

where $\mathrm{COI}_{c}=$ cube-per-order index for class $c, f_{d}=$ density for products (i.e., unit load $/ \mathrm{m}^{2}$ ), $I_{p c}^{t}=$ storage level in the unit 


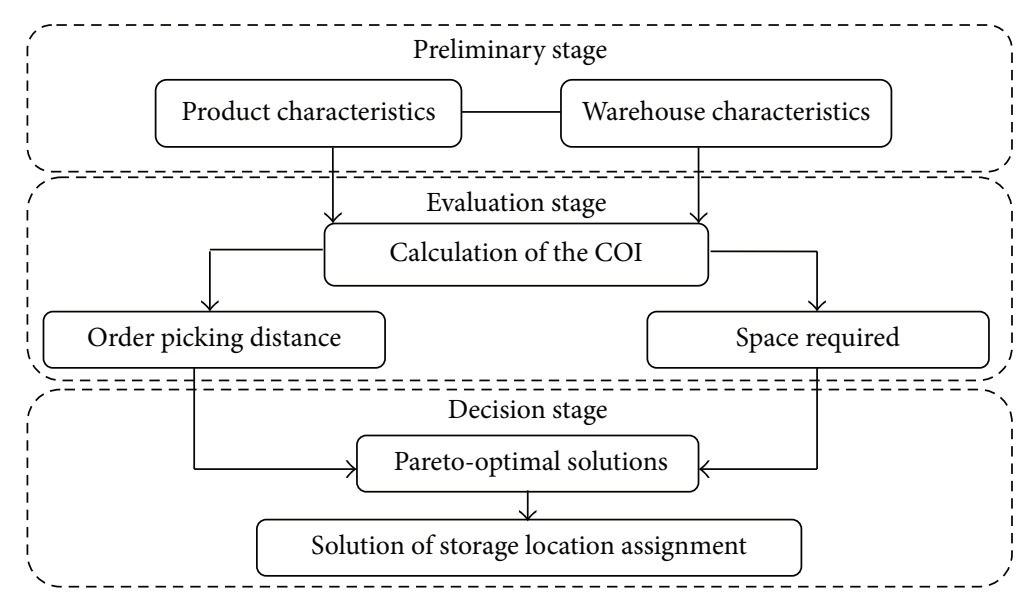

Figure 1: Steps of the proposed methodology.

loads planned for product $p$ during period $t$ in class $c$, and $D_{p c}=$ total number of picks for product $p$ in class $c$.

The location of the items must follow the ascending order of the index. Based on the COI, there is a tendency for products with lower space requirements and high demand to be located in front of the store (i.e., next to the I/O) and products with greater space requirements and low demand to be located far from the I/O. Thus, the COI tries to make storage more efficient by minimizing the distances with a single control for order picking [39].

To illustrate the application of the COI, let us assume a warehouse in two dimensions (2D) with 5 columns $(x)$ and 17 rows $(y)$ which is available to allocate products divided into cells of $1 \mathrm{~m} \times 1 \mathrm{~m}$, as shown in Figure 2 .

In this example, the characteristics of the products will vary with the total space required and the demand. In this way, four different ranges of these characteristics, which range from high to low, were proposed. To calculate the space required, the density (i.e., size) of the products and the amount in storage during a specific interval of time were used. Moreover, four weeks is considered to represent a typical month. Thus, the demand amount is a median estimated based on forecasts and/or orders for a week. This information is presented in Table 1. Importantly, the difference between the demands of the product may be different to those in storage because of the economic lot size, safety stocks, and so forth.

Firstly, the COI is calculated for a dedicated storage system. From the ascending order of the index, the products are located in the warehouse from the I/O to the back. From this initial storage assignment it is possible to calculate the average distance to order picking. Only the direction $y$ in Figure 2 was considered because the products are being picked by single order picking (i.e., one per route). The picker always exits from the $\mathrm{I} / \mathrm{O}$ point and follows the row $y$ where the product is located. He then returns to the I/O. Thus, there is no significant displacement in the direction $x$. Table 2 illustrates the steps for obtaining a dedicated storage policy.

Table 2 shows that the position of the products in storage follows the order $P_{4}, P_{2}, P_{3}$, and $P_{1}$. As a result, this policy

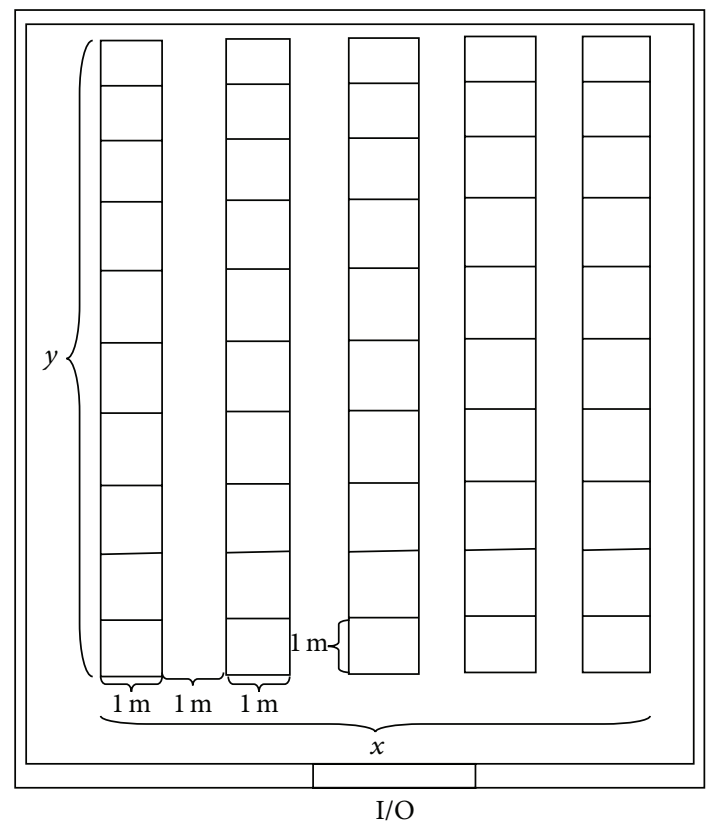

FIGURE 2: Illustration of the layout of the storage area in the warehouse Adapted from Fontana and Cavalcante [38].

needs a total space of $85 \mathrm{~m}^{2}$ and a total order picking distance of 357.5 meters. Importantly, twice this total distance is required for total order picking (i.e., round trip). The reduction of the space required is possible in some cases during the class-based storage formation, as shown in Table 3.

Using the policy without space reduction, when there is a class-based formation (e.g., $P_{2}+P_{4}$ ), the largest space requirement for each product is verified first. Afterwards, these requirements are summed for all products in storage. When space reduction is considered, the space required for all of the products within the same class-based storage is summed. Then, the space required for this class-based is considered. If the largest space requirement (i.e., peak) of 
TABLE 1: Example of product characteristics used in this study.

\begin{tabular}{lcccccccc}
\hline \multirow{2}{*}{ Product $\left(P_{i}\right)$} & \multirow{2}{*}{ Space } & Demand & Density $\left(\mathrm{m}^{2} / \mathrm{un}\right)$ & \multicolumn{3}{c}{ Total space required $\left(\mathrm{m}^{2}\right)$} & \multicolumn{2}{c}{ Demand/period (units) } \\
\hline$P_{1}$ & High & Low & 6.20 & 35 & 30 & 30 & 30 & 5 \\
$P_{2}$ & High & High & 0.79 & 25 & 30 & 30 & 25 & 35 \\
$P_{3}$ & Low & Low & 0.75 & 10 & 5 & 10 & 5 & 10 \\
$P_{4}$ & Low & High & 0.25 & 5 & 5 & 5 & 10 & 25 \\
\hline
\end{tabular}

Adapted from Muppani and Adil [27].

TABLE 2: Product location in the dedicated storage system using COI.

\begin{tabular}{|c|c|c|c|c|c|c|c|c|c|c|c|c|}
\hline \multirow{2}{*}{ Class } & \multirow{2}{*}{$P_{i}$} & \multicolumn{4}{|c|}{ Space $\left(\mathrm{m}^{2}\right)$} & \multirow{2}{*}{$\operatorname{Max}^{*}$} & \multirow{2}{*}{$\begin{array}{l}\text { Demand }(A) \\
\text { (units) }\end{array}$} & \multirow{2}{*}{$\mathrm{COI}$} & \multirow{2}{*}{ Place } & \multirow{2}{*}{$\begin{array}{l}\text { Required rows }\left(y_{i}\right) \\
\quad\left(y_{i}=\operatorname{Max} / x\right)\end{array}$} & \multirow{2}{*}{$\begin{array}{l}\text { Average distance } \\
\text { (B) }(\mathrm{m})\end{array}$} & \multirow{2}{*}{$\begin{array}{l}\text { Total distance } \\
\qquad(C=A * B)\end{array}$} \\
\hline & & 1 & 2 & 3 & 4 & & & & & & & \\
\hline 1 & $P_{1}$ & 35 & 30 & 30 & 30 & 35 & 5 & 7.00 & 4 & 7 & 13.5 & 67.5 \\
\hline 2 & $P_{2}$ & 25 & 30 & 30 & 25 & 30 & 35 & 0.85 & 2 & 6 & 5.0 & 175.0 \\
\hline 3 & $P_{3}$ & 10 & 5 & 10 & 5 & 10 & 10 & 1.00 & 3 & 2 & 9.0 & 90.0 \\
\hline \multirow[t]{2}{*}{4} & $P_{4}$ & 5 & 5 & 5 & 10 & 10 & 25 & 0.40 & 1 & 2 & 1.0 & 25.0 \\
\hline & & & Total & space & & 85 & & & & 17 & & 357.5 \\
\hline
\end{tabular}

${ }^{*}$ Max = maximum space required.

Adapted from Muppani and Adil [27].

TABLE 3: Space reduction by class-based formation.

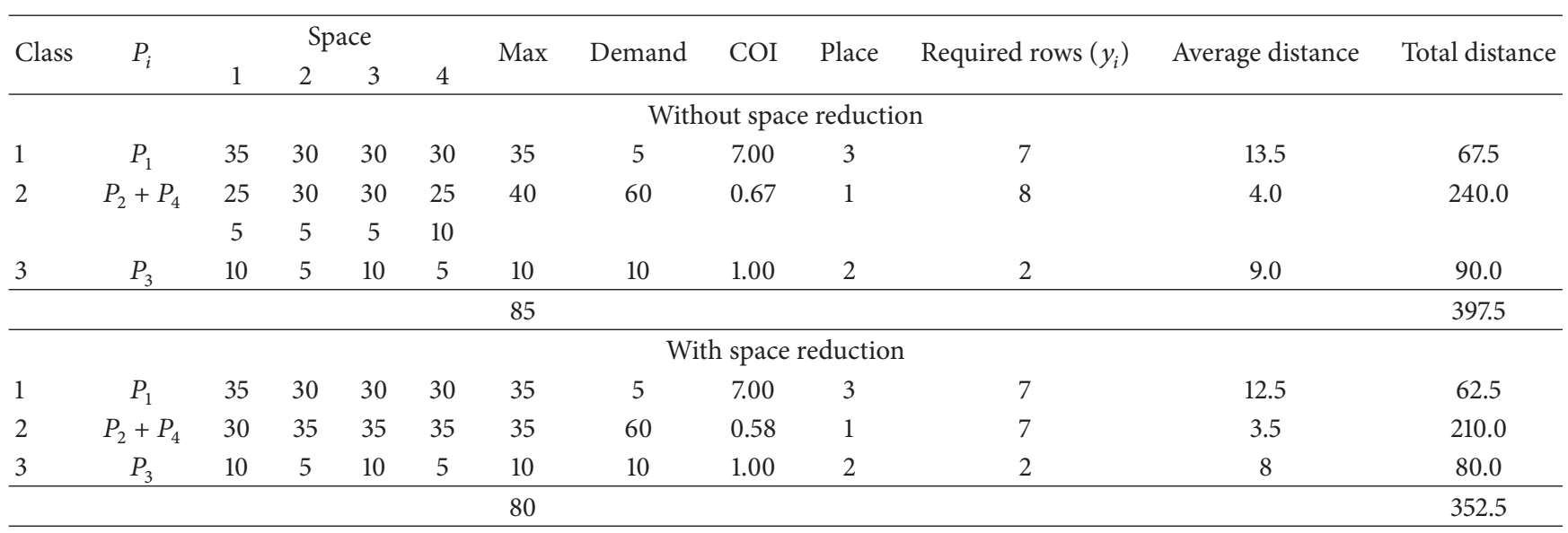

Adapted from Muppani and Adil [27].

each product in the same class-based occurs in different periods, a space reduction is possible.

Table 4 summarizes all possible setups of the class-based storage and their requirements of space $(S)$ and order picking distance $(O P)$. All class-based storage is formed from the initial location (i.e., dedicated storage), as shown in Table 2. The alternatives can be generated from a deterministic manner; that is, we can test all possible combinations or we can use a heuristic method for that. The choice will depend on the number of products in the warehouse, since the larger the number of products, the greater the number of possible combinations of storage location, making the complex problem, and thus a deterministic method may fail to resolve the problem. In this work we will not emphasize heuristic methods, because this is well crystallized in several works as that of Muppani and Adil [24, 27]. Our main goal is to demonstrate the existing tradeoff between the space required and the order picking distance in warehouse.

Table 4 shows that there are two important values in the storage location assignment: order picking distance and space required. Assuming that, for example, only the space required is considered, the better alternative is the single class-based or random system $(e)$ because this yields the smallest space required. However, this allocation creates the greatest order picking distance. Conversely, the alternative $(b)$ shows the smallest order picking distance but requires a space greater 
TABLE 4: Summary of class-based storage generated by the COI.

\begin{tabular}{|c|c|c|c|c|}
\hline Alternative & Class & Product & $S$ & $\mathrm{OP}$ \\
\hline \multirow{4}{*}{$\mathrm{a}$} & 1 & $P_{1}$ & \multirow{4}{*}{85} & \multirow{4}{*}{357.5} \\
\hline & 2 & $P_{2}$ & & \\
\hline & 3 & $P_{3}$ & & \\
\hline & 4 & $P_{4}$ & & \\
\hline \multirow{3}{*}{$\mathrm{b}$} & 1 & $P_{1}$ & \multirow{3}{*}{80} & \multirow{3}{*}{352.5} \\
\hline & 2 & $P_{2} P_{4}$ & & \\
\hline & 3 & $P_{3}$ & & \\
\hline \multirow{3}{*}{ c } & 1 & $P_{1} P_{3}$ & \multirow{3}{*}{85} & \multirow{3}{*}{387.5} \\
\hline & 2 & $P_{2}$ & & \\
\hline & 3 & $P_{4}$ & & \\
\hline \multirow{2}{*}{ d } & 1 & $P_{1} P_{3}$ & \multirow{2}{*}{80} & \multirow{2}{*}{382.5} \\
\hline & 2 & $P_{2} P_{4}$ & & \\
\hline $\mathrm{e}$ & 1 & $P_{1} P_{2} P_{3} P_{4}$ & 75 & 562.5 \\
\hline \multirow{2}{*}{$\mathrm{f}$} & 1 & $P_{2} P_{3} P_{4}$ & \multirow{2}{*}{80} & \multirow{2}{*}{377.5} \\
\hline & 2 & $P_{1}$ & & \\
\hline \multirow{2}{*}{ g } & 1 & $P_{4}$ & \multirow{2}{*}{80} & \multirow{2}{*}{475.0} \\
\hline & 2 & $P_{1} P_{2} P_{3}$ & & \\
\hline \multirow{3}{*}{ h } & 1 & $P_{2} P_{3}$ & \multirow{3}{*}{85} & \multirow{3}{*}{362.5} \\
\hline & 2 & $P_{1}$ & & \\
\hline & 3 & $P_{4}$ & & \\
\hline
\end{tabular}

Adapted from Muppani and Adil [27].

than (e). Thus, the use of a Pareto-optimal curve or efficient Frontier is proposed to aid in this tradeoff (i.e., space required versus order picking distance).

2.3. Decision Stage. From the prior stage, it is assumed that the DM decides to implement an alternative for storage location assignment based on a Pareto-optimal solution. As previously mentioned, this solution takes into account two criteria or objectives: the space required and the order picking distance.

2.3.1. Efficient Frontier. In systems with multiple objectives, the objectives are often in conflict with one another where one objective function value must be "traded off" for another. There are two approaches to solve these problems: the first approach combines all of the objectives into a single composite function and moves all but one objective to the constraint set and the second approach determines the Pareto-optimal solution set or an efficient frontier, which is a set of points in the objective function space that is often referred to as a tradeoff curve $[40,41]$. The efficient frontier is defined as the locus of achievable joint evaluations from which no joint gains are possible [42].

The underlying premise of the modern Paretian construction is individualistic: the individual himself is assumed to be the only one who is able to measure or to quantify his own utility or satisfaction. No external observer is presumed able to make comparisons of utility among separate individuals. It is possible, however, even within these limits, to develop

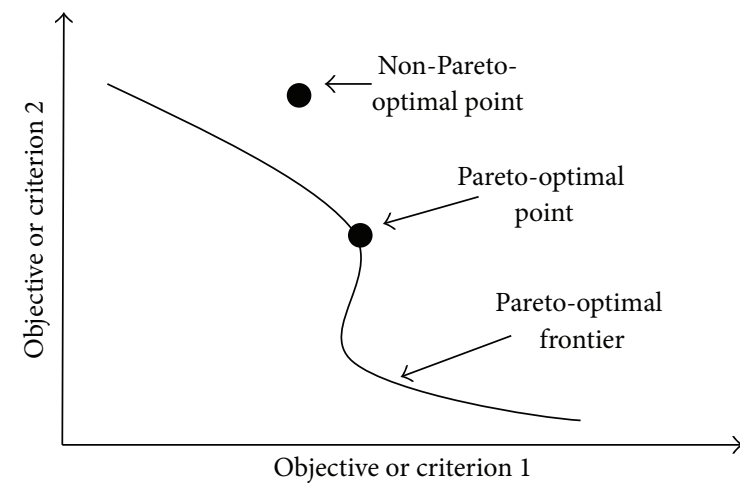

Figure 3: Pareto-optimal points and Pareto frontier.

a means of evaluating either "situations" or "changes in situations" in terms of their "efficiency." To do this, a very weak ethical postulate is proposed. The "welfare" of the whole group of individuals is said to be increased if (1) every individual in the group is made better off or (2) at least one member in the group is made better off without anyone being made worse off [43].

Let $M$ be the set of points admissible and let $J$ be the set of criteria/objectives. Alvarez-Vázquez et al. [44] defined the Pareto-optimal solution as follows.

Definition 1. $m=\left(m_{1}, \ldots, m_{N}\right) \in M$ is a Pareto-optimal solution of problem $(P)$ if there does not exist any $m^{*} \in M$ such that $J_{j}\left(m^{*}\right) \leq J_{j}(m)$, for all $j=\{1,2, \ldots, N E\}$, and for at least one $j \in\{1,2, \ldots, N E\}, J_{j}\left(m^{*}\right)<J_{j}(m)$.

If $m \in M$ is a Pareto-optimal solution, the objective vector $\left(J_{1}(m), \ldots, J_{N E}(m)\right) \in \mathbb{R}^{N E}$ is also known as Pareto-optimal. The set of Pareto-optimal solutions is called a Pareto-optimal set and the set of Pareto-optimal objective vectors is called a Pareto-optimal frontier. Figure 3 shows the Pareto-optimal curve.

In Figure 3, it can be seen that there are points that are not part of the solution because they are dominated solutions and are known as non-Pareto-optimal points. In addition to these points, there are points on the efficient frontier (i.e., the nondominated solutions) and are known as a Pareto-optimal frontier. Finally, the point of the optimal solution (i.e., the Pareto-optimal point) is also shown. The latter makes part of the set of nondominated solutions and is one that yields the best benefit to the DM or group of DMs. In other words, when analyzing a single decision with a single DM, the Paretooptimal solution is the point where any gain on a criterion will lead to a loss in another when analyzing all feasible points.

Depending on the criteria examined, the Pareto-optimal point may not be evident and requires that the DM performs the trade-off analysis between the nondominated alternatives. In this paper, for example, there are two criteria: the space required by each alternative and the order picking distance. As a result, there may be a set of solutions that are nondominated whose values are such that it is difficult to say which one is the Pareto-optimal. For example, there are two alternatives, 
such as $\mathrm{A}=\{$ space $=200$, order picking $=1000\}$ and $\mathrm{B}=$ $\{$ space $=150$; order picking $=1100\}$. To choose between $A$ and $\mathrm{B}$, the DM will have to consider other criteria intrinsic to their preferences, such as the costs involved and the influence of the level of customer service.

\section{Description of the Simulation}

This simulation was based on the work of Fontana and Cavalcante $[38,39]$. It was initially assumed that the picking operations were performed under a single command, and all items were stored and transported in identical manners. Each storage location was uniformly used and points were distributed homogeneously in the space allotted for the classbased storage. This assumption implies that the geometric center of the class-based is the same as the load center.

It is assumed that the inventory decision is made independently of the storage decision and that all the time required in the process of storage, except the picking time, is independent of storage location assignment. The analysis considered four periods, with each period representing a week, forming a total of one month.

The warehouse simulated was rectangular and was divided into cells of $1.0 \times 1.0$ meters, as shown in Figure 2 . The layout used in the warehouse consisted of five columns ( $x$ direction in Figure 2). The use of space in the $y$ direction was not restricted, which did not represent a significant aspect in the simulation. It was found that all products were stacked with up to 10 levels high.

Four scenarios were generated randomly. The quantities demanded were in the range of 60 to 1500 units weekly. The demand used in the calculations was the average of the four periods. The inventory (i.e., the quantity of items in storage) was the ratio of the average demand and a random variable, which simulated the variations of units stored in each period. The values of the quantities demanded and inventoried were rounded upwards to have integer values of products.

The space required was related to the inventory. Thus, the space used was calculated as the inventory multiplied by the product density and divided by the 10 possible levels (i.e., the maximum height of a product stack). It is shown that there will be an oscillation of the space required in each of the four periods. The density of the products is 0 to $1 \mathrm{~m}^{2} /$ unit and must always be not equal to zero.

The simulated warehouse has five distinct products, and all of the products considered in the first period are assumed to be used up in the following periods. The values presented in the course of the simulations refer to the average (i.e., these values represented only one period). The order picking distances represent a round trip, always starting at the I/O.

\section{Results and Analysis}

There are two objectives $f_{1}(x)$ and $f_{2}(x)$ in this work: space required and the order picking distance. In both the DM wants the same goal; that is, he wants the alternative with the least space required and the least order picking distance. However, the values were normalized on a scale from 0 to 1 , where the worst alternative was (0) and the best was (1). Thus, in this case, the DM wants the maximization of the result. So, the problem formulation is shown as follows:

$$
\begin{array}{ll}
\operatorname{Max} & Z=\left(f_{1}(x), f_{2}(x)\right) \in \mathbb{R}^{N E} \\
\text { s.t. } \quad & x \in X^{*} \\
& f_{j}\left(x^{*}\right) \leq f_{j}(x) \\
& f_{j}\left(x^{*}\right) \neq f_{j}(x) \\
& \forall j=\{1,2, \ldots, N E\},
\end{array}
$$

where $X$ is the decision space, $x=\left\{x_{1}, x_{2}, \ldots, x_{n}\right\}$ is a vector of decision, and $X^{*}$ is the set of feasible solutions.

The alternatives were generated from deterministic manner; that is, we tested all possible combinations, respecting the information described above. In real case, with a larger number of alternatives, we can use a heuristic method for generating the alternatives. Table 5 presents the space required in $\mathrm{m}^{2}$ and the order picking distance in $\mathrm{m}$ by the set of viable alternatives in the four simulated cases.

In general, the dedicated storage system used more space than the random storage system. However, this results in larger order picking distances because its average load center is greater than the dedicated storage system. For example, in Table 2, the dedicated storage system shows the average load center (i.e., average distance) as 1.0, 5.0, 9.0, and 13.5 meters, respectively, while the random storage system has a value of 7.5 meters. This number multiplied by the demand results in an order picking distance of 562.5 meters, while the dedicated storage system yields an order picking distance of 357.5 meters. However, when space reduction is possible, the random storage system yields a large reduction in space and can result in the least space required. Moreover, the random storage system requires a much greater control of inventory, requiring pickers to know the exact location of each product. In the dedicated storage system, this control is smaller because the pickers are already familiar with the location of each item (i.e., it makes the order picking activity easier.).

These alternatives (i.e., dedicated and random storage systems) show the conflicts between the objectives considered. Thus, the efficient frontier is considered. Figure 4 shows the efficient frontier, which is composed by the following alternatives: random, class-based 11 and class-based 13 in the first case (see Figure 4(a)), class-based 4 and class-based 12 (these had the same results), random, class-based 14 in the second case (see Figure 4(b)), random, class-based 4 and class-based 14 in the third case (see Figure 4(c)), and finally, random and class-based 14 in the last case (see Figure 4(d)).

In this case, the number of nondominated alternatives was greatly reduced. So, it was not necessary to use any sophisticated methods to obtain the efficient frontier. Thus, noting only the efficient frontier, the DM can eliminate most of the alternatives of storage location assignments; however, he does not reach the final decision only with this step. Therefore, he should then check the real needs of the warehouse. For example, if the warehouse is leased, the 
TABLE 5: Set of viable alternatives.

\begin{tabular}{|c|c|c|c|c|c|c|c|c|}
\hline \multirow{2}{*}{ Alternatives } & \multicolumn{2}{|c|}{ Case 1} & \multicolumn{2}{|c|}{ Case 2} & \multicolumn{2}{|c|}{ Case 3} & \multicolumn{2}{|c|}{ Case 4} \\
\hline & Space & Distance & Space & Distance & Space & Distance & Space & Distance \\
\hline Dedicated & 0.00 & 0.07 & 0.00 & 0.41 & 0.00 & 0.00 & 0.00 & 0.56 \\
\hline Random & 1.00 & 0.00 & 1.00 & 0.00 & 1.00 & 0.49 & 1.00 & 0.36 \\
\hline \multicolumn{9}{|l|}{ Class-based } \\
\hline 01 & 0.41 & 0.57 & 0.62 & 0.99 & 0.48 & 0.66 & 0.07 & 0.05 \\
\hline 02 & 0.19 & 0.38 & 0.38 & 0.72 & 0.70 & 0.98 & 0.02 & 0.04 \\
\hline 03 & 0.19 & 0.35 & 0.00 & 0.41 & 0.24 & 0.47 & 0.02 & 0.03 \\
\hline 04 & 0.65 & 0.57 & 0.95 & 1.00 & 0.89 & 1.00 & 0.21 & 0.06 \\
\hline 05 & 0.35 & 0.49 & 0.39 & 0.72 & 0.81 & 0.74 & 0.16 & 0.66 \\
\hline 06 & 0.35 & 0.47 & 0.01 & 0.40 & 0.35 & 0.52 & 0.16 & 0.65 \\
\hline 07 & 0.22 & 0.29 & 0.62 & 0.99 & 0.24 & 0.19 & 0.05 & 0.57 \\
\hline 08 & 0.00 & 0.10 & 0.38 & 0.72 & 0.46 & 0.51 & 0.00 & 0.56 \\
\hline 09 & 0.35 & 0.29 & 0.49 & 0.67 & 0.81 & 0.53 & 0.18 & 0.01 \\
\hline 10 & 0.35 & 0.26 & 0.11 & 0.36 & 0.35 & 0.31 & 0.18 & 0.00 \\
\hline 11 & 0.81 & 1.00 & 0.62 & 0.88 & 0.59 & 0.53 & 0.19 & 0.67 \\
\hline 12 & 0.46 & 0.29 & 0.95 & 1.00 & 0.65 & 0.53 & 0.19 & 0.58 \\
\hline 13 & 0.89 & 0.92 & 0.62 & 0.10 & 0.59 & 0.29 & 0.20 & 0.03 \\
\hline 14 & 0.81 & 0.21 & 0.96 & 0.88 & 1.00 & 0.90 & 0.98 & 1.00 \\
\hline
\end{tabular}

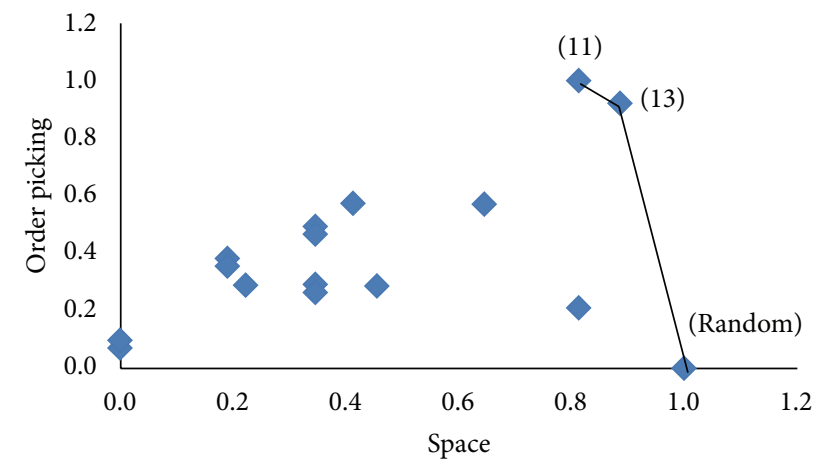

(a) Case 1

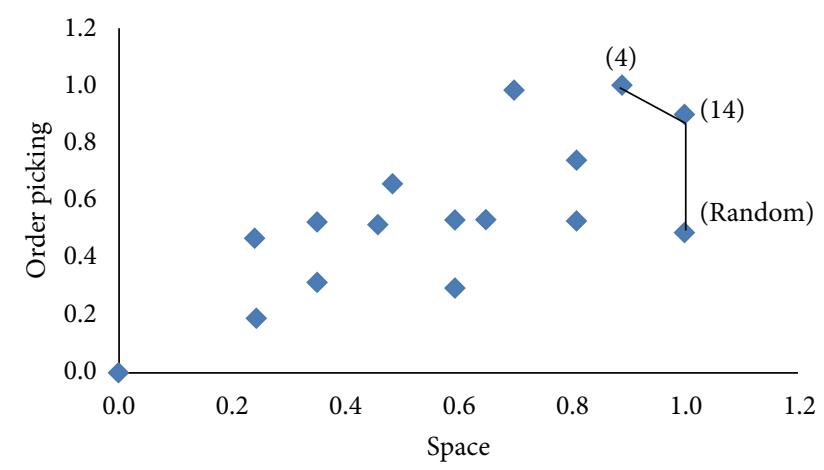

(c) Case 3

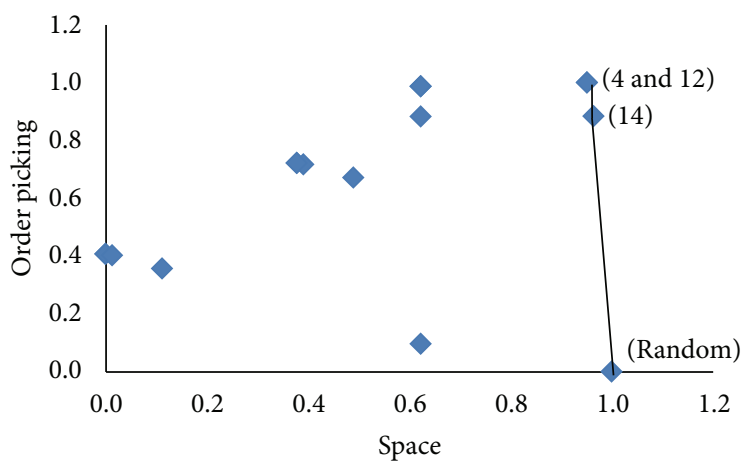

(b) Case 2

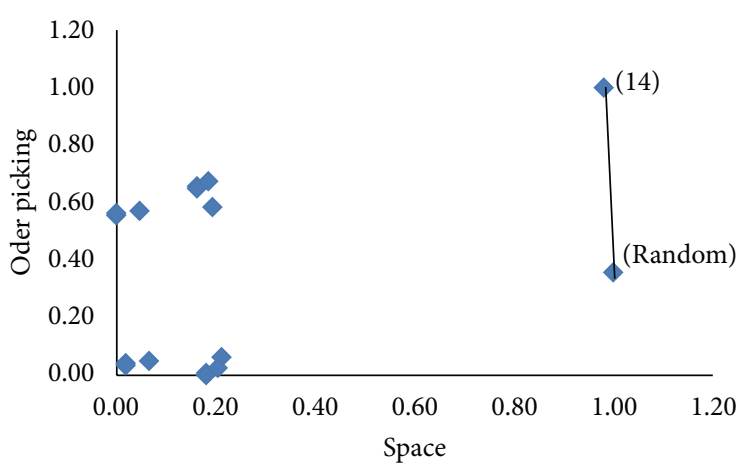

(d) Case 4

FIgURE 4: The efficient frontier for the four cases simulated.

DM will probably prefer an alternative that minimizes the space used. However, if the customers are very demanding of the response time of their orders, the DM will prefer an alternative that provides lower order picking distance. Moreover, he can use other criteria that can aid in the final decision. However, this additional analysis should be performed only for the alternatives in the efficient frontier. The final result will change according to the type of each warehouse and the DM's preferences.

Therefore, the biggest gain of this efficient frontier analysis, compared to other methods, is the graphical visualization of the behavior of alternatives, where it is very clear what 
alternatives are dominated and which deserve more attention, that is, those which are not dominated. In the case analyzed, the efficient frontier makes this in a simpler manner than other multiobjective methods.

\section{Concluding Remarks}

The main variables that influence the efficiency of a warehouse were shown to be the space required and the order picking distance. These variables were explored in this study as criteria/objectives, in which the DM aims to find an alternative to storage location assignment that minimizes both variables. To evaluate these criteria, it was noted that the current literature uses the associated costs. However, in practice, many DMs have difficulties in quantifying these costs accurately, especially with regard to the opportunity cost of space not used. Therefore, this paper suggested the adoption of a Pareto-optimal solution or efficient frontier to analyze the alternatives of storage location assignment. It was found that most of the alternatives are dominated (i.e., the DM has a reduced set of solutions) by a few optimal solutions.

It is emphasized that the Pareto-optimal will depend on the needs of the warehouse, the costs inherent to their activities, and the DM's preferences. However, the use of Pareto-optimal makes the final decision easer and improves visualization of the behavior of the available alternatives.

As a suggestion for future work, a practical application of this methodology should be constructed. The following step may be to attempt to include the preferences of the DM about the alternatives on the efficient frontier. Furthermore, in a situation where there are a larger number of alternatives, it would be interesting to study the use of a heuristic method to solve this problem.

\section{Conflict of Interests}

The authors declare that there is no conflict of interests regarding the publication of this paper.

\section{References}

[1] F. Ballestín, A. Pérez, P. Lino, S. Quintanilla, and V. Valls, "Static and dynamic policies with RFID for the scheduling of retrieval and storage warehouse operations," Computers \& Industrial Engineering, vol. 66, no. 4, pp. 696-709, 2013.

[2] A. Alonso-Ayuso, G. Tirado, and Á. Udías, “On a selection and scheduling problem in automatic storage and retrieval warehouses," International Journal of Production Research, vol. 51, no. 17, pp. 5337-5353, 2013.

[3] K. Roodbergen and I. Vis, "A model for warehouse layout," IIE Transactions, vol. 38, no. 10, pp. 799-811, 2006.

[4] A. H. Azadnia, S. Taheri, P. Ghadimi, M. Z. Mat Saman, and K. Y. Wong, "Order batching in warehouses by minimizing total tardiness: a hybrid approach of weighted association rule mining and genetic algorithms," The Scientific World Journal, vol. 2013, Article ID 246578, 13 pages, 2013.

[5] R. Accorsi, R. Manzini, and F. Maranesi, "A decision-support system for the design and management of warehousing systems," Computers in Industry, vol. 65, no. 1, pp. 175-186, 2014.
[6] C. H. Y. Lam, K. L. Choy, G. T. S. Ho, and C. K. M. Lee, "An order-picking operations system for managing the batching activities in a warehouse," International Journal of Systems Science, vol. 45, no. 6, pp. 1283-1295, 2014.

[7] Y.-F. Chuang, H.-T. Lee, and Y.-C. Lai, "Item-associated cluster assignment model on storage allocation problems," Computers \& Industrial Engineering, vol. 63, no. 4, pp. 1171-1177, 2012.

[8] Ö. Öztürkoğlu, K. R. Gue, and R. D. Meller, "A constructive aisle design model for unit-load warehouses with multiple pickup and deposit points," European Journal of Operational Research, vol. 236, no. 1, pp. 382-394, 2014.

[9] C. Jane and Y. Laih, "A clustering algorithm for item assignment in a synchronized zone order picking system," European Journal of Operational Research, vol. 166, no. 2, pp. 489-496, 2005.

[10] M. C. Chen, C. L. Huang, K. Y. Chen, and H. P. Wu, "Aggregation of orders in distribution centers using data mining," Expert Systems with Applications, vol. 28, no. 3, pp. 453-460, 2005.

[11] I. van Nieuwenhuyse and R. B. M. de Koster, "Evaluating order throughput time in 2-block warehouses with time window batching," International Journal of Production Economics, vol. 121, no. 2, pp. 654-664, 2009.

[12] J. Gu, M. Goetschalckx, and L. F. McGinnis, "Research on warehouse operation: a comprehensive review," European Journal of Operational Research, vol. 177, no. 1, pp. 1-21, 2007.

[13] M.-C. Chen and H.-P. Wu, "An association-based clustering approach to order batching considering customer demand patterns," Omega, vol. 33, no. 4, pp. 333-343, 2005.

[14] C. G. Petersen and G. Aase, "A comparison of picking, storage, and routing policies in manual order picking," International Journal of Production Economics, vol. 92, no. 1, pp. 11-19, 2004.

[15] R. de Koster, T. Le-Duc, and K. J. Roodbergen, "Design and control of warehouse order picking: a literature review," European Journal of Operational Research, vol. 182, no. 2, pp. 481-501, 2007.

[16] J. Gu, M. Goetschalckx, and L. F. McGinnis, "Research on warehouse design and performance evaluation: a comprehensive review," European Journal of Operational Research, vol. 203, no. 3, pp. 539-549, 2010.

[17] S. Henn, "Algorithms for on-line order batching in an order picking warehouse," Computers and Operations Research, vol. 39, no. 11, pp. 2549-2563, 2012.

[18] S. Henn, S. Koch, K. F. Doerner, C. Strauss, and G. Wäscher, "Metaheuristics for the order batching problem in manual order picking systems," Business Research, vol. 3, no. 1, pp. 82-105, 2010.

[19] Y.-C. Chou, Y.-H. Chen, and H.-M. Chen, "Recency-based storage assignment and warehouse configuration for recurrent demands," Computers and Industrial Engineering, vol. 62, no. 4, pp. 880-889, 2012.

[20] A. Kovács, "Optimizing the storage assignment in a warehouse served by milkrun logistics," International Journal of Production Economics, vol. 133, no. 1, pp. 312-318, 2011.

[21] N. Boysen and K. Stephan, "The deterministic product location problem under a pick-by-order policy," Discrete Applied Mathematics, vol. 161, no. 18, pp. 2862-2875, 2013.

[22] C.-M. Liu, "Clustering techniques for stock location and orderpicking in a distribution center," Computers and Operations Research, vol. 26, no. 10-11, pp. 989-1002, 1999.

[23] R. A. Moura, Manual Logistics: Warehousing and Physical Distribution, vol. 2, IMAM, São Paulo, Brazil, 1997. 
[24] V. R. Muppani and G. K. Adil, "Efficient formation of storage classes for warehouse storage location assignment: a simulated annealing approach," Omega, vol. 36, no. 4, pp. 609-618, 2008.

[25] B. Rouwenhorst, B. Reuter, V. Stockrahm, G. J. van Houtum, R. J. Mantel, and W. H. M. Zijm, "Warehouse design and control: framework and literature review," European Journal of Operational Research, vol. 122, no. 3, pp. 515-533, 2000.

[26] F. T. S. Chan and H. K. Chan, "Improving the productivity of order picking of a manual-pick and multi-level rack distribution warehouse through the implementation of class-based storage," Expert Systems with Applications, vol. 38, no. 3, pp. 2686-2700, 2011.

[27] V. R. Muppani and G. K. Adil, "A branch and bound algorithm for class based storage location assignment," European Journal of Operational Research, vol. 189, no. 2, pp. 492-507, 2008.

[28] M. E. Fontana and C. A. V. Cavalcante, "Electre tri method used to storage location assignment into categories," Pesquisa Operacional, vol. 33, no. 2, pp. 283-303, 2013.

[29] N. Meghelli-Gaouar and Z. Sari, "Assessment of performance of a class-based storage in a flow-rack AS/RS," Journal of Studies on Manufacturing, vol. 1, pp. 100-107, 2010.

[30] H. Brynzér and M. I. Johansson, "Storage location assignment: using the product structure to reduce order picking times," International Journal of Production Economics, vol. 46-47, pp. 595-603, 1996.

[31] R. L. Daniels, J. L. Rummel, and R. Schantz, "A model for warehouse order picking," European Journal of Operational Research, vol. 105, no. 1, pp. 1-17, 1998.

[32] J. C.-H. Pan and M.-H. Wu, "A study of storage assignment problem for an order picking line in a pick-and-pass warehousing system," Computers and Industrial Engineering, vol. 57, no. 1, pp. 261-268, 2009.

[33] S. Ene and N. Öztürk, "Storage location assignment and order picking optimization in the automotive industry," Journal of advanced manufacturing Technology, vol. 60, pp. 787-797, 2012.

[34] J. Xiao and L. Zheng, "Correlated storage assignment to minimize zone visits for BOM picking," International Journal of Advanced Manufacturing Technology, vol. 61, no. 5-8, pp. 797807, 2012.

[35] J. P. Van Den Berg, "Class-based storage allocation in a singlecommand warehouse with space requirement constraints," International Journal of Industrial Engineering, vol. 3, no. 1, pp. 21-28, 1996.

[36] F. Guerriero, R. Musmanno, O. Pisacane, and F. Rende, "A mathematical model for the multi-levels product allocation problem in a warehouse with compatibility constraints," Applied Mathematical Modelling, vol. 37, no. 6, pp. 4385-4398, 2013.

[37] H. Chen, Y. Zhu, L. Ma, and B. Niu, "Multiobjective RFID network optimization using multiobjective evolutionary and swarm intelligence approaches," Mathematical Problems in Engineering, vol. 2014, Article ID 961412, 13 pages, 2014.

[38] M. E. Fontana and C. A. V. Cavalcante, "Use of Promethee method to determine the best alternative for warehouse storage location assignment," International Journal of Advanced Manufacturing, vol. 70, pp. 1615-1624, 2014.

[39] M. E. Fontana and C. A. V. Cavalcante, "Using the number of clients for class formation and location of the items to minimize the distance traveled for picking," in Proceedings of the 30th Encontro Nacional de Engenharia de Produção (ENEGEP '10), pp. 1-13, São Carlos, Brazil, 2010.
[40] M. Fleischer, "Scale invariant pareto optlmallty a metaformalism for characterizing and modeling cooperativity in evolutionary systems," in Genetic and Evolutionary Computation Conference (GECCO’ 05), pp. 233-240, New York, NY, USA, June 2005.

[41] N. Jawahar, S. G. Ponnambalam, K. Sivakumar, and V. Thangadurai, "Heuristics for multiobjective optimization of two-sided assembly line systems," The Scientific World Journal, vol. 2014, Article ID 458959, 16 pages, 2014.

[42] H. Raiffa, The Art and Science of Negotiation. How to Resolve Conflicts and Get the Best Out of Bargaining, The Belknap Press of Harvard University Press, 1982.

[43] J. M. Buchanan, The Calculus of Consent: Logical Foundations of Constitutional Democracy, vol. 3, Liberty Fund, 1962.

[44] L. J. Alvarez-Vázquez, N. García-Chan, A. Martínez, and M. E. Vázquez-Méndez, "Pareto-optimal solutions for a wastewater treatment problem," Journal of Computational and Applied Mathematics, vol. 234, pp. 2193-2201, 2010. 


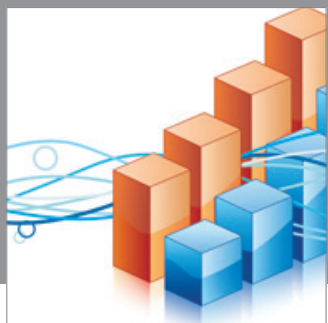

Advances in

Operations Research

mansans

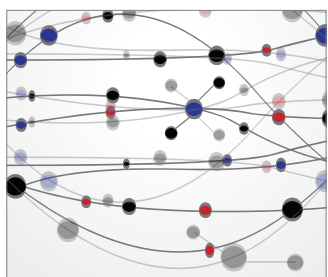

The Scientific World Journal
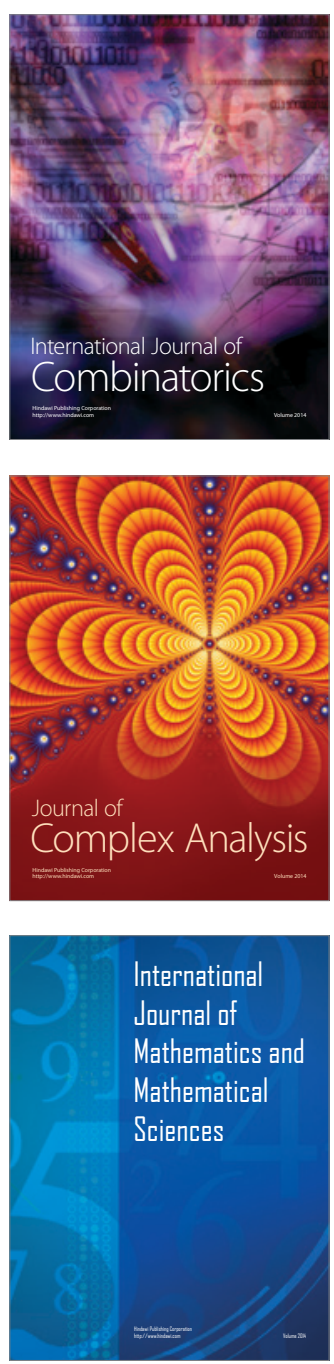
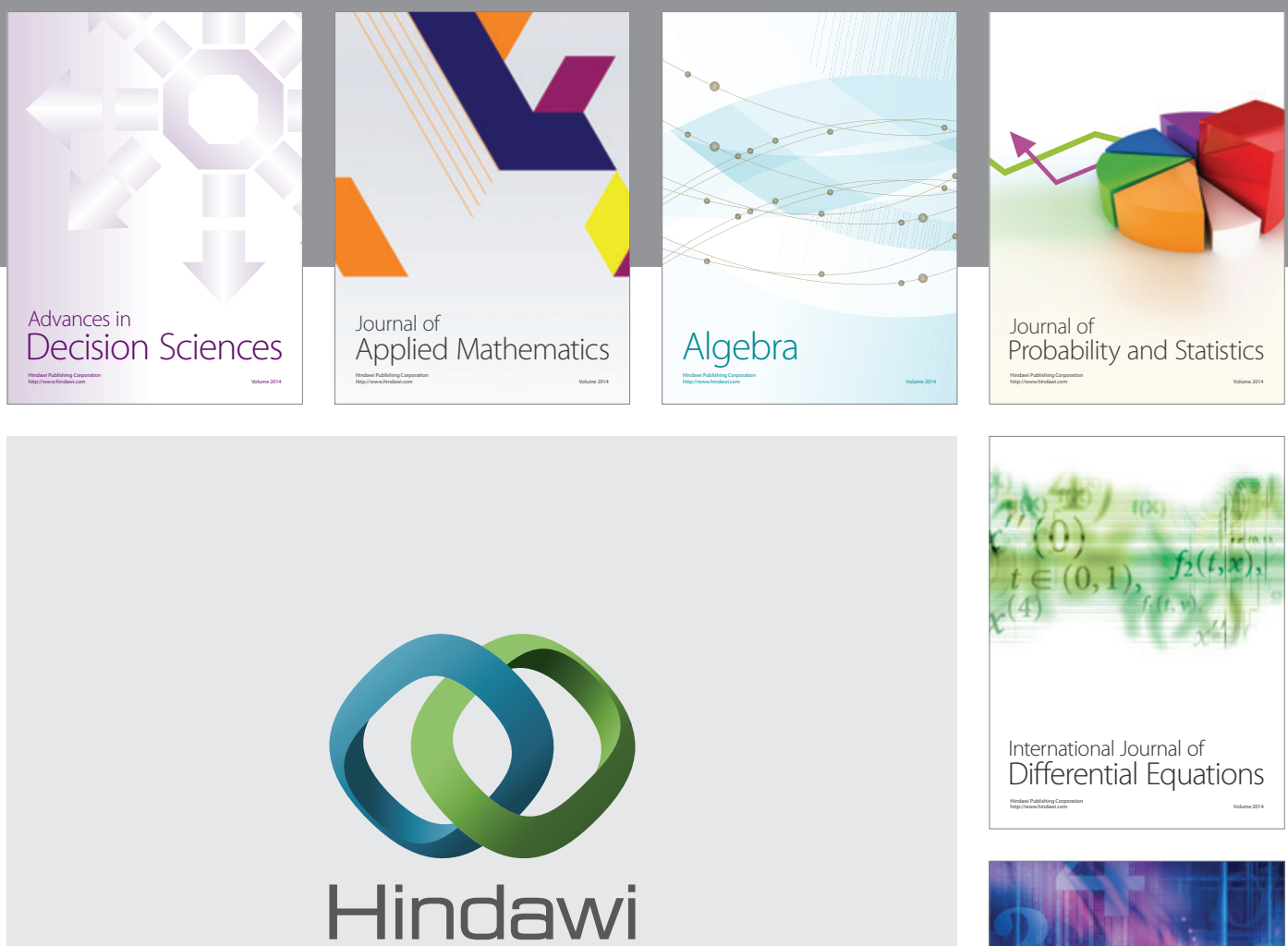

Submit your manuscripts at http://www.hindawi.com
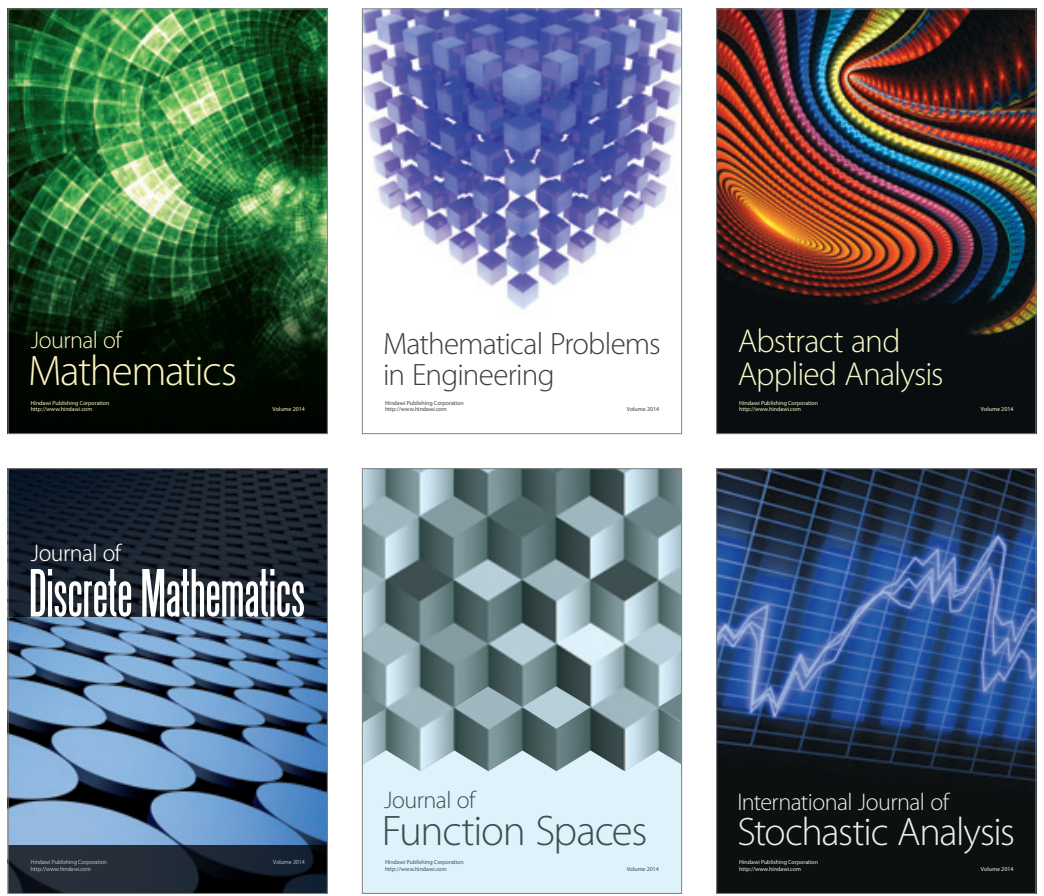

Journal of

Function Spaces

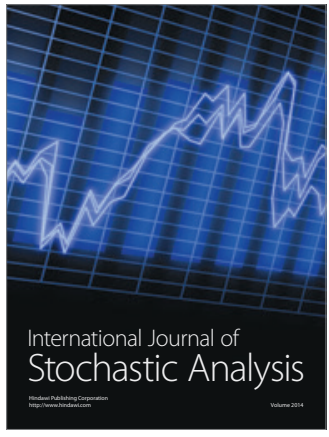

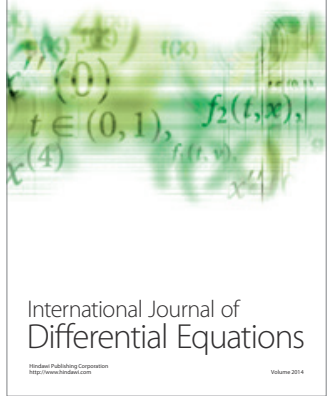
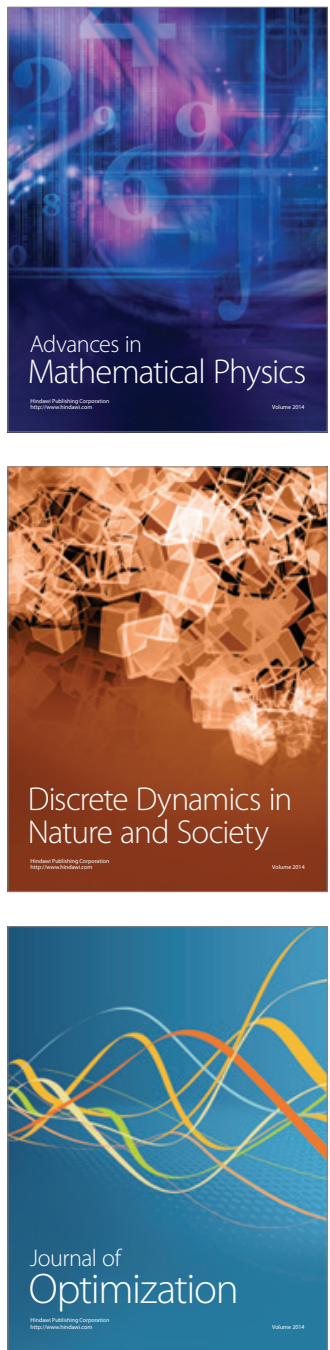